\title{
Performance variation of Li rechargeable cells having polypyrrole cathodes doped with different anions
}

\author{
K.P. Vidanapathirana* and Kumudu Perera \\ Department of Electronics, Faculty of Applied Sciences, Wayamba University of Sri Lanka, Kuliyapitiya.
}

\begin{abstract}
Electrochemically synthesized polymers such as polypyrrole (PPy), polyaniline (PANI) and polyNmethyl pyrrole (PNMP) are considered as one of the most promising polymer electrode material groups for the development of advanced electrochemical devices such as electrochemical cells, super capacitors, electrochromic devices and solar cells. The properties of electrochemically synthesized polymers are known to be largely dependent on the dopant anion used and hence, their performance in applications also depend greatly upon the dopants. In this study, the role of the anion used to dope the PPy cathode on the performance of a lithium (Li) rechargeable cell is reported. Anions were varied from small inorganic anions $\left(\mathrm{CF}_{3} \mathrm{SO}_{3}^{-}\right)$to large anions (alkilsulphonate, $\mathrm{AS}^{-}$and dodeclybenzenesulphonate, DBS-). PPy was electropolymerized and the cells were fabricated with a polyacrylonitrile (PAN) based solid polymer electrolyte (SPE) while Li served as the anode. Cyclic voltammetry and continuous charge discharge tests were carried out to characterize the cells. The cycling results showed better cycling charge and long cycle life with the cells fabricated with PPy doped with large anions. The cells with large anions showed higher cycle numbers while the cells with inorganic anions could not be cycled over 350 cycles. Even with electrodes having larger anions, better results can be obtained with slow scan rates. Scanning electron microscopy (SEM) studies revealed that electrodes have a porous morphology with smaller anions and a dense morphology with larger anions, which also affect the performance variations.
\end{abstract}

Keywords: Cyclic voltammetry, morphology, polyacrylonitrile, polypyrrole.

\section{INTRODUCTION}

Electrochemically synthesized polymers or conjugated polymers (CP) are considered as one of the most promising polymer electrode material groups for the development of advanced electrochemical devices since they have interesting features such as appreciable electronic conductivity, low cost, easy handling and environmental friendliness (Cheng et al., 2006; Huang, 2006; Wang et al., 2006; Green et al., 2010). Some of the interesting applications of CPs are in electrochemical cells, super capacitors, electrochromic devices and solar cells. As such, a large amount of work has been carried out to explore different conjugated polymers. Among them a considerable interest has been devoted to polypyrrole (PPy) based cells due to some of their special features such as longer cycle life, lower self discharge rate, endurance to over discharging, low manufacturing cost and shape flexibility. During the synthesizing of $\mathrm{CPs}$, different anions are introduced to the polymer backbone and it has been found that the properties of such polymer electrodes vary depending on the type of the anions used (Skaarup et al., 2000; 2003). In this study, the role of the anion used to dope the PPy cathode for the performance of $\mathrm{Li}$ rechargeable cells is reported. The structure of the cell is $\mathrm{Li} /$ gel polymer electrolyte / PPy cathode doped with different anions. The gel polymer electrolyte consists of polyacrylonitrile (PAN), ethylene carbonate (EC), propylene carbonate (PC) and lithiumtrifluoromethanesulfonate $\left(\mathrm{LiCF}_{3} \mathrm{SO}_{3}\right)$.

\section{METHODS AND MATERIALS}

The monomer pyrrole (Aldrich) was purified by distillation under nitrogen atmosphere and stored in the dark at low temperature. Polypyrrole films were galvanostatically deposited on a stainless steel dice using a current density of $1 \mathrm{~mA} \mathrm{~cm}{ }^{-2}$ in an electrochemical cell where platinum and $\mathrm{Ag} / \mathrm{AgCl}$ electrodes served as the counter and the reference electrodes, respectively. 
The thickness of the films were set to be $1 \mu \mathrm{m}$. Aqueous solutions of $0.5 \mathrm{M}$ sodium dodecylbenzenesulphonate (SDBS) (Aldrich), sodium alkylsulphonate (SAS) and lithiumtrifluoromethanesulfonate (lithiumtriflate) $\left(\mathrm{LiCF}_{3} \mathrm{SO}_{3}\right)$ were used as the electrolytes for doping pyrrole. Dodecylbenzenesulphonate (DBS) and alkylsulphonate (AS) anions are known to be larger in size compared to triflate $\left(\mathrm{CF}_{3} \mathrm{SO}_{3}\right)$ anion. Preparation of PAN based gel polymer electrolyte with $\mathrm{LiCF}_{3} \mathrm{SO}_{3}$ as the salt and $\mathrm{EC}$ and $\mathrm{PC}$ as plasticisers was done using the hot press method (Perera et al., 2000).

The cells were fabricated inside an argon filled glove box. The PPy deposited on the stainless steel dice was used as the cathode. A circular disc with the same diameter as the cathode cut from the gel polymer electrolyte membrane was used as the electrolyte or the separator. A lithium electrode of the identical diameter as the electrolyte served as the anode. A brass sample holder was used to house the whole cell assembly.

Cyclic voltammetry tests were first carried out for the cells in the potential range $2.2-3.5 \mathrm{~V}$ using a computer controlled potentiostat / galvanostat. While the PPy electrodes served as the working electrode, lithium was used as both the counter and reference electrodes. Cells were cycled at different scan rates. Thereafter these cells were tested for their ability to withstand continuous charge and discharge cycling. The cells were first galvanostatically discharged to $2.0 \mathrm{~V}$, immediately subjected to a galvanostatic charge up to $3.5 \mathrm{~V}$ and maintained at that potential until the desired current was reached and then discharged using a computer controlled charge-discharge setup. The maximum charge and discharge currents were set to $25 \mu \mathrm{A}$.

In order to study the morphologies of the PPy cathodes, scanning electron microscopy (SEM) studies were carried out. For SEM studies, films of $10 \mu \mathrm{m}$ thickness were deposited on indium tin oxide (ITO) glass.

\section{RESULTS}

The resulting cyclic voltammograms for cells having PPy : $\mathrm{X}\left(\mathrm{CF}_{3} \mathrm{SO}_{3}^{-}, \mathrm{DBS}^{-}, \mathrm{AS}^{-}\right)$electrodes of $1 \mu \mathrm{m}$ thickness are shown in Figure 1.

Almost all the cells had open circuit voltages between $3.0-3.5$ V. Peaks appeared at cathodic and anodic scans, but with increasing scan rates, the appearance of the peaks became weaker and also the peak separation became larger. However, the peak separation in cells using PPy with larger anions is smaller compared to PPy with $\mathrm{CF}_{3} \mathrm{SO}_{3}$. The areas of the curves tend to decrease with increasing scan rate.

The capacity variations with cycle number are shown in Figure 2 for each cell. A cell containing the electrode doped with a small anion has a lower cycle life. Also, it has undergone a severe problem in charging and discharging after 200 cycles. The cell with PPy : AS electrode also has faced the problem around the $700^{\text {th }}$ cycle. The other cell has initially undergone a problem but seems to have recovered.

SEM photographs obtained for the films doped with the three types of anions considered are shown in Figure 3.

A cauliflower nature morphology, which is known to be porous is available with the PPy : triflate electrode. PPy : DBS are of dense morphology while PPy : AS films are in between porous and dense natures.

\section{DISCUSSION AND CONCLUSION}

The cathodic peak (negative current) of the cyclic voltammogram is assigned to the reduction and the anodic peak (positive current) is assigned to the oxidation (Tang et al., 2010), i.e. peaks at cyclic voltammograms exhibit the potentials at which redox reactions of the cells at charging (oxidation) and discharging (reduction) take place. If the reactions are well reversible, the ion insertion and deinsertion in and out to the cathode during charging and discharging occurs at identical potentials during each cycle. Hence, the corresponding peaks should appear at the same potential values resulting zero peak separation. At high scan rates, oxidation and reduction processes cannot follow those high rates and hence, those reactions that should occur at a particular potential does not occur. Instead, that potential shifts increasing the peak separation (Vidanapathirana et al., 2000; Cherian et al., 2012). Also, at high scan rates, the redox reactions may not take place completely and therefore, the sharp peaks may not be seen in the curves. The areas of cyclic voltammograms refer to the total charge that exist during cell reactions. With the decreasing area upon increasing scan rate, it reveals that the available charge during fast scan rates is very low. Hence, in order to get the use of the whole charge, cells should be cycled at slow scan rates (Kim et al., 2008).

The low separation between charge (oxidation) and discharge (reduction) curves in the graphs of capacity 
(a)

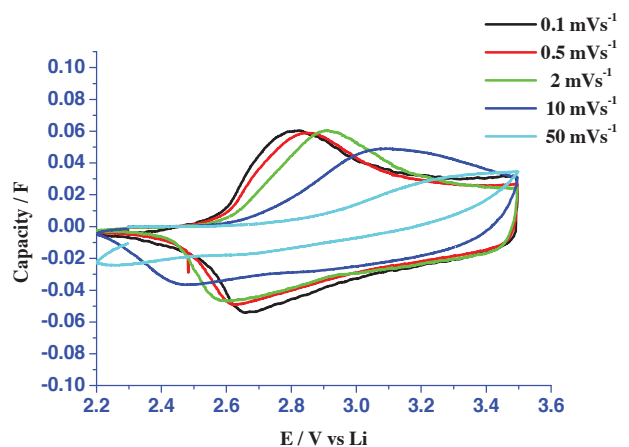

(b)

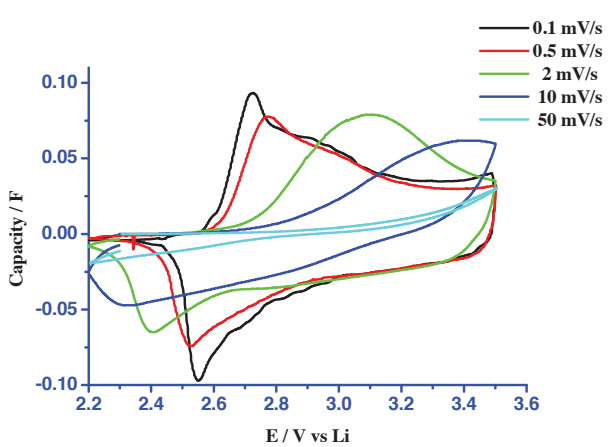

(c)

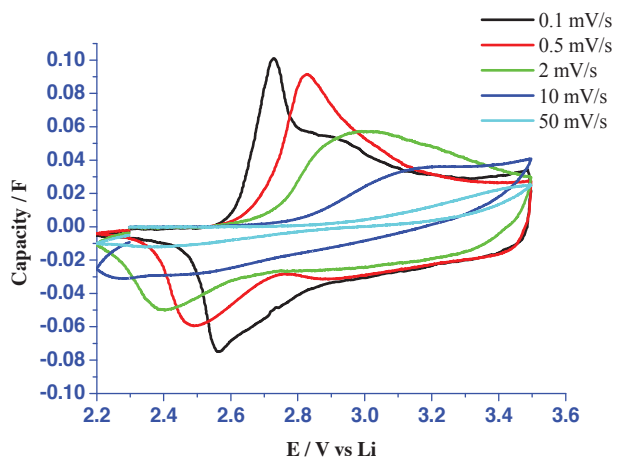

Figure 1: Cyclic Voltammograms obtained for the cells of the configuration, Li/PAN:EC:PC:/PPy:X $\mathrm{X}$ : (a) Triflate $\left(\mathrm{CF}_{3} \mathrm{SO}_{3}^{-}\right)$; (b) Alkylsulphonate $\left(\mathrm{AS}^{-}\right)$(c) Dodecylbenzenesulphonate (DBS ${ }^{-}$)

(a)

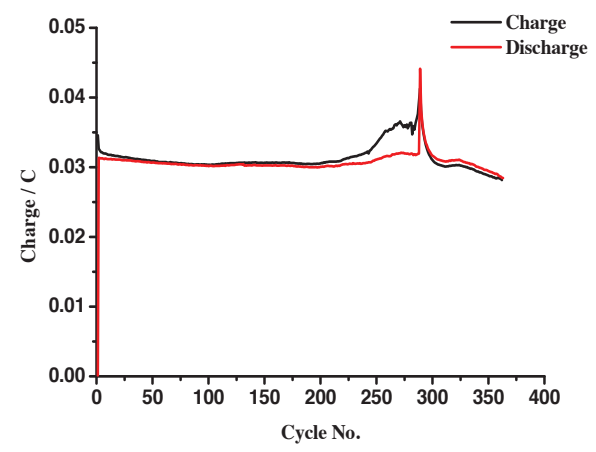

(b)

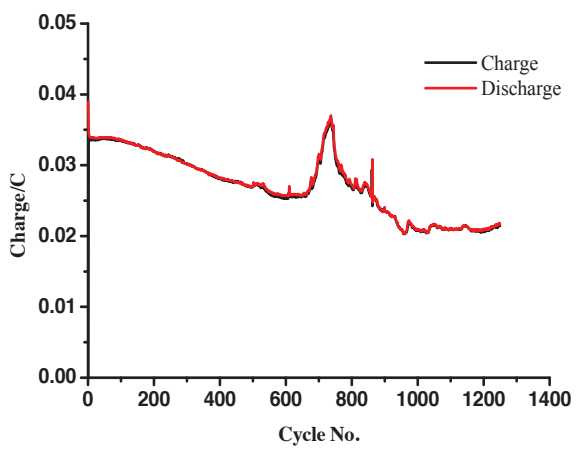

(c)

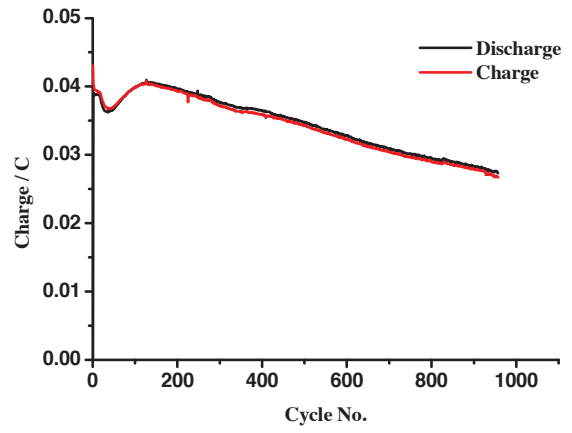

Figure 2: Capacity variation with cycle number for cells with PPy: $\mathrm{X}$ having film thickness of $1 \mu \mathrm{m}$ $\mathrm{X}$ : (a) Triflate $\left(\mathrm{CF}_{3} \mathrm{SO}_{3}^{-}\right)$; (b) Alcylsulphonate $\left(\mathrm{AS}^{-}\right)$; (c) Dodecylbenzenesulphonate (DBS ${ }^{-}$) 


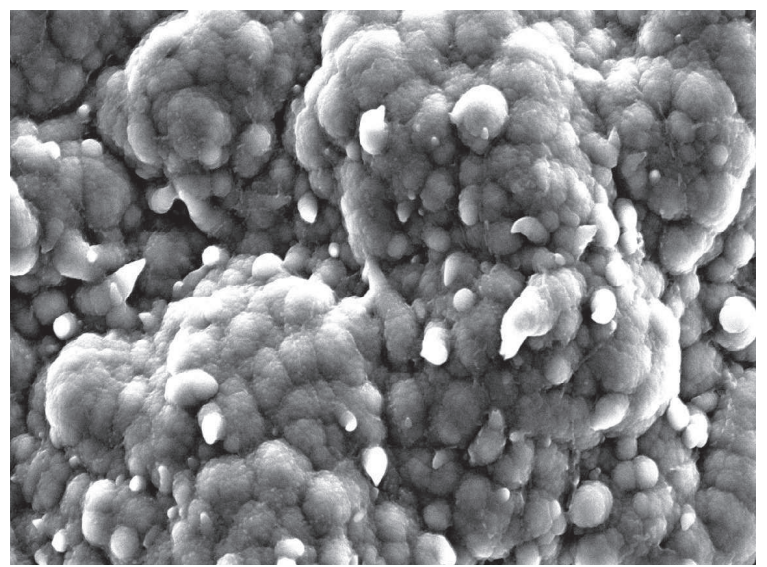

(a)

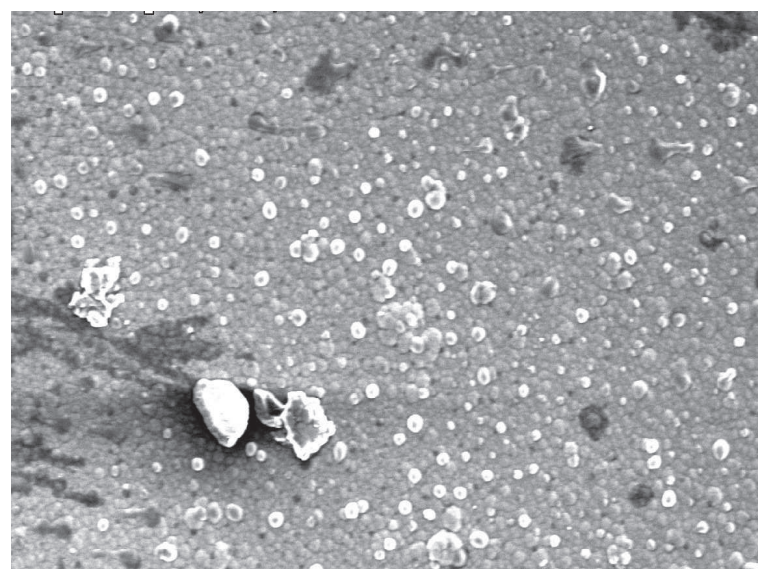

(b)

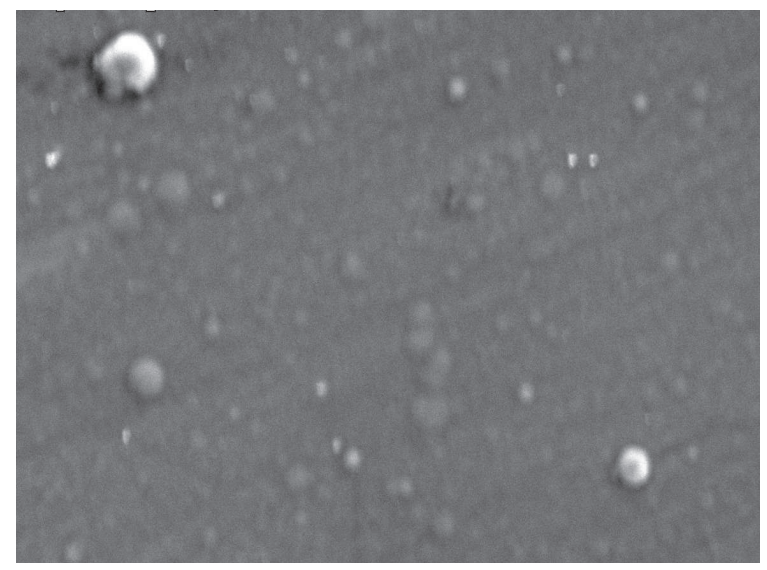

(c)

Figure 3: SEM photograpgh of PPy: $\mathrm{X}$

$\mathrm{X}:$ (a) Triflate $\left(\mathrm{CF}_{3} \mathrm{SO}_{3}^{-}\right)$; (b) Alcylsulphonate $\left(\mathrm{AS}^{-}\right)$; (c) Dodecylbenzenesulphonate (DBS $)$. Magnification: $1.2 \mathrm{k}$.

versus cycle number (Figure 2) indicates the existence of kinetic reversibility. Amongst the most specified characteristics in cells having electrodes doped with larger anions is the retention of charge factor, which is defined as the ratio between the charge and the discharge capacities close to unity. This indicates the absence of parasitic reactions, which may cause higher charge capacities than discharge capacities. The cells with larger anions showed higher cycle numbers while the cell with inorganic smaller anion could not be cycled over 350 cycles. An unusual behaviour was seen in the cell with PPy : AS of $1 \mu \mathrm{m}$ thickness. During around the $111^{\text {th }}$ cycle, building up of a high resistance has occurred leading to difficulty of charging. It could be due to short circuiting with lithium. The morphology of PPy : AS films, which are more closer to porous nature may also be responsible for this. Some irreversible capacity losses in cells may be attributed to the contact area and shorter diffusion length in thin electrode films (Zhu \& Lu, 2012).

From Figure 3, it is clear that the PPy / DBS has a dense morphology. In literature, it is reported that electrode films having dense morphology may give rise to slow redox activities and therefore poor cell performances (Melato et al., 2009). Accordingly, the cells with DBS electrodes should exhibit poor performances and lower capacities. However, the cells tested had higher capacities than the porous cathode PPy / $\mathrm{CF}_{3} \mathrm{SO}_{3}$. This may be due to the fact that the former fulfills the requirement of slow ion diffusion for a longer period of time to obtain pure capacitive or full charge storage, so that they show comparatively higher capacities. 
Porous morphology is considered to have faster redox reactions (Osaka et al., 1997). Therefore, it is possible to result in lower capacities and this fact is clearly proven with the results obtained for the cell having PPy / triflate, which is of porous morphology. Also, the electrodes having a porous nature attain purely capacitive state quickly and they have less amount of cycleable charge. Hence, they show less capacity.

The shorter cycle life of the cells with $\mathrm{PPy}: \mathrm{CF}_{3} \mathrm{SO}_{3}$ electrode may be also due to its porous nature, which has more probability for short circuiting.

The dopant anion of PPy plays an important role in the performance of Li rechargeable cells. PPy doped with larger anions are more suitable as cathode material than those doped with smaller inorganic anions. Even with larger anions, cells should be cycled at slow scan rates in order to allow all cell reactions to take place efficiently and effectively.

\section{Acknowledgement}

The assistance given by the International Programme for Physical Sciences (IPPS), Uppsala, Sweden is highly acknowledged.

\section{REFERENCES}

1. Cheng F., Tang W., Li C., Chen J., Liu H., Shen P. \& Dou S. (2006). Conducting poly(aniline) nanotubes and nanofibers: controlled synthesis and application in lithium/poly(aniline) rechargeable batteries. Chemistry A European Journal 12(11): 3082 - 3088. DOI: http://dx.doi.org/10.1002/chem.200500883

2. Cherian C.T., Reddy M.V., Rao G.V.S., Sow C.H. \& Chowdari B.V.R. (2012). Li cycling properties of nano crystalline $\left(\mathrm{Ni}_{1-\mathrm{x}} \mathrm{Zn}_{\mathrm{x}}\right) \mathrm{Fe}_{2} \mathrm{O}_{4}$. Journal of Solid State Electrochemistry 16: 1823 - 1832.

DOI: http://dx.doi.org/10.1007/s10008-012-1662-2

3. Green R.A., Baek S., Warren L.A.P. \& Martens P.J. (2010). Conducting polymer hydro gels for medical electrode applications. Science and Technology of Advance Materials 11(1): $1-13$.

DOI: http://dx.doi.org/10.1088/1468-6996/11/1/014107

4. Huang J. (2006). Synthesis and applications of conducting polymer polyaniline nanofiberes. Pure and Applied
Chemistry 78(1): 15 - 27.

DOI: http://dx.doi.org/10.1351/pac200678010015

5. Kim J.S., Ahn H.J., Kim I.P., Kim K.W., Ahn J.H., Park C.W. \& Ryu H.S. (2008). Short term cycling properties of $\mathrm{Na} / \mathrm{PVdF} / \mathrm{S}$ battery at ambient temperatures. Journal of Solid State Electrochemistry 12: 861 - 865.

DOI: http://dx.doi.org/10.1007/s10008-008-0504-8

6. Melato A.I., Mendonca M.H. \& Abrantes L.M. (2009). Effect of the electropolymerization conditions on the electrochemical, morphological and structural properties of PEDOTh films. Journal of Solid State Electrochemistry 13: $417-426$.

DOI: http://dx.doi.org/10.1007/s10008-008-0522-6

7. Osaka T., Momma T., Ito H. \& Scrosati B. (1997). Performances of lithium/gel electrolyte/polypyrrole secondary batteries. Journal of Power Sources 68(2): 392 $-396$.

8. Perera K., Dissanayake M.A.K.L. \& Bandaranayake P.W.S.K. (2000). Copper ion conducting solid polymer electrolyte based on polyacrylonitrile. Electrochim Acta 45: $1361-1369$.

9. Perera K., Dissanayake M.A.K.L., Skaarup S. \& West K. (2008). Application of polyacrylonitrile based polymer electrolytes in rechargeable Li batteries. Journal of Solid State Electrochemistry 12: 873 - 877.

DOI: http://dx.doi.org/10.1007/s10008-007-0479-x

10. Skaarup S., Lasse B., Vidanapathirana K., Thybo S., Tofte P. $\&$ West K. (2003). Symultaneous anion and cation mobility in polypyrrole. Solid State Ionics 159: 143 - 147.

11. SkaarupS., WestK., Gunarathne L.M.W.K., Vidanapathirana K.P. \& Careem M.A. (2000). Determination of ionic carriers in polypyrrole. Solid State Ionics 136/137: 577 - 582.

12. Tang Z., Wu J., Li Q., Lan Z., Fan L., Lin J. \& Huang M. (2010). The preparation of poly(glycidyl acrylate)polypyrrole gel-electrolyte and its application in dyesensitized solar cells. Electrochim Acta 55: 4883 - 4888. DOI: http://dx.doi.org/10.1016/j.electacta.2010.03.081

13. Vidanapathirana K.P., Perera K. \& Careem M.A. (2000). Application of conducting polymer (polypyrrole) as an electrode in Li rechargeable batteries Proceedings of the Technical Sessions, Institute of Physics 16: 88 - 96.

14. Wang J., Wang C.Y., Too C.O. \& Wallace G.G. (2006). Highly-flexible fibre battery incorporating polypyrrole cathode and carbon nanotubes anode. Journal of Power Sources 161: 1458 - 1462.

DOI: http://dx.doi.org/10.1016/j.jpowsour.2006.05.038

15. Zhu J. \& Lu L. (2012). Cycling effects on interfacial reliability of $\mathrm{TiO}_{2}$ anode film in thin film $\mathrm{Li}$ ion microbatteries. Journal of Solid State Electrochemistry 16: $1877-1881$.

DOI: http://dx.doi.org/10.1007/s10008-011-1545-y 